\title{
Phoenix Tree, Phoenix and Empress: Empress Historical-Cultural Symbol of Phoenix Tree and its Good Environmental Civilized Value
}

\author{
Wu Zhiwen ${ }^{1 *}$, Wu Songyuan ${ }^{2}$ and Yang Shujun ${ }^{3}$ \\ ${ }^{1}$ Guangyuan Forestry Bureau, Sichuan Province, 628000, China \\ 2School of Mathematical Science, Beijing Normal University, 100875, China \\ ${ }^{3}$ The Standing Committee of the People's Congress of Lizhou District, Guangyuan City, Sichuan Province, 628000, China \\ ×Corresponding author: Dr. Wu Zhiwen, Guangyuan Forestry Bureau, Sichuan Province, 628000, China; Tel: 15328581105; Email: 948384567@qq.com
}

Received: November 03, 2021; Accepted: November 11, 2021; Published: November 29, 2021

\begin{abstract}
This paper is intended to analyze the interrelation, mutual influence and integration of phoenix tree, phoenix and empress in ecological and cultural terms. The study indicates the historical-cultural symbolical meaning of Empress Wu of phoenix tree, and the ecological value. Empress Wu is the incarnation of dragon, rebirth of Maitreya Buddha with godship. From aspect of theology, phoenix stays at phoenix tree that is a myth by means of phoenix tree; phoenix and dragon keep abreast, phoenix represents outstanding woman, and Empress Wu is the incarnation of phoenix (super holy bird). Phoenix liked to stay on phoenix tree (super sacred tree), therefore, phoenix tree represents the body of empress. In Buddhism, phoenix tree's imagery being the sacred tree of Chinese Buddhism is its feature, which is formed when the tree is cultivated in religious temple. Empress Wu is a human with humanity. In forest culture, imagery of phoenix tree is of aesthetic culture which represents pure love subjective intention by means of phoenix tree in gardens planting of past dynasties and composition of poetry. Love imagery of phoenix tree and phoenix symbolizes human emotion of Empress Wu. Lofty imagery of phoenix tree symbolizes the only one empress in China. That falling leaves of phoenix tree shows autumn comes symbolized Empress Wu lost her Kingship and became queen for the rest of her life. Aesthetic cultural connotation, consisting of nobleness and hope of phoenix and misery and sad of phoenix tree, symbolized people's comment to Empress $\mathrm{Wu}$ in the past one thousand and three hundred years. Ecological value of phoenix imagery: nine holy birds which perch at bronze divine trees of Sanxingdui, and Sunbird of the Jinsha Site gives an impression that golden bird carries the sun to soar in the universe; in human's mental concept, phoenix tree symbolizes habitat for humanity of ecological civilization, and phoenix symbolizes human's dream of flying. Phoenix likes to stay on phoenix tree, which symbolizes harmonious civilization of human and human's earnest hope for good life.
\end{abstract}

Keywords: Phoenix tree; Phoenix; Sacred tree of Chinese Buddhism; Empress culture

Phoenix tree and phoenix culture are well-known in China. It is of profound practical significance to associate the phoenix tree and phoenix with Empress Wu, the only empress in Chinese history, and thus to study the empress culture. The composite image of phoenix tree and phoenix contains Empress Wu's divinity, emperor and female humanity as a "the incarnation of dragon" and "rebirth of Maitreya Buddha with godship", full of mystery, solemnity, humanity and historical and cultural sense. Phoenix tree and phoenix culture and the empress culture are integrated with each other, so that the phoenix tree blends into people's subjective sentiments and aesthetic ideals of Empress $\mathrm{Wu}$ [1], and becomes an aesthetic image to examine the empress culture.

\section{Phoenix Tree, Phoenix and the Empress}

\section{The Phoenix Tree}

The phoenix tree, also known as Qingtong, Chinese phoenix tree, Biwu, Qingyu, and Tingwu, belongs to the deciduous tree of the
Sycamonaceae family. "The fertile soil is suitable for planting phoenix trees." Phoenix trees have long become garden ornamental trees and important greening trees in China. They are suitable for lawns, courtyards, front houses, slopes, roadsides, solitary planting around lakes or cluster planting. The phoenix tree, collocated with palm, bamboo, plantain, etc. could convey a sense of harmony. "A tranquil house may have phoenix trees planted in the front, and green bamboos at the back. The front eave provides space to take a leisure walk under it. Covert windows are set in the north, which are closed in spring and winter to protect the room from wind and rain. While in summer and autumn, they are opened to get the room ventilated. Planting phoenix trees is full of joy: in spring and winter, sunlight fall through the sparse branches, bathing the people sitting against the trunk in the warmth, while in summer and autumn, the dense branches form a canopy for people to seek shade from the scorching sun." [2] There are extremely abundant scientific culture and poetry creations about the phoenix tree, forming a unique phoenix tree culture [3]. 


\section{The Phoenix}

The oldest phoenix pattern found in China has a history of 7,400 years. Dragon and Phoenix are the two totem systems of the Chinese nation. The ancients used an animal, a plant, or a creature in the nature as a symbol to represent the lineage of a clan or group, and respected it as a patron to worship. Such a symbol is called a "totem". The phoenix is a totem image evolved from the patron imagined by the ancients. It is said that the Shang tribe among the descendants of the Yellow Emperor used to be the bird totem tribe, and this bird was called the "Phoenix Bird". The Book of Songs · Song of Shang · Xuan Niao says, "The emperor ordered Xuan Niao (another name of phoenix in ancient times) to come to the world and give birth to Qi, who later established the Shang Dynasty." The ancestor of the Shang Dynasty, Qi, was born by Xuan Niao, who later established a powerful Shang Dynasty. Xuan Niao is the Phoenix. From the bronzes unearthed in the Shang and Zhou dynasties, we can see the carved phoenix pattern. "The singing phoenix in Qishan mountain heralds a prosperous era of Zhou" "Blowing flute to attract the phoenix." So the phoenix bird became the holy bird that blessed the people of Zhou. The allusion of "the phoenix sings in Qishan mountain" made the phoenix a symbol of Zhou's prosperity. This is why there are a lot of phoenix patterns in the bronzes of the Western Zhou Dynasty. There is a sentence in The Book of Songs . Daya, "The phoenix flies to the sky in the wind... The phoenix sings on the high hills, heralding auspiciousness." It also talks about the allusion about "the phoenix sings in Qishan mountain". Therefore, in the Western Zhou Dynasty, the phoenix was regarded as a mystical mascot. Later, as the tribes united or annexed each other, various totems were compounded for many times, thereby resulting in totems with strange images such as dragons and phoenixes. The phoenix and the dragon are always inseparable till today. The holy bird, phoenix, is beautiful, auspicious, kind, peaceful, virtuous, and blessing of the nature. For Chinese, worshiping phoenixes is a strong national complex in that the phoenix is a symbol of nobility and dignity.

As the incarnation of the royal woman's mascot, "Phoenix" was first seen in an allusion. According to the legend, when Yao abdicated to Shun, and Shun abdicated to Yu, all of people celebrated and all the beasts also came to congratulate, including the phoenix. The "Dragon and Phoenix Pattern" painted pottery flask was unearthed at the Yangshao Cultural Site in Beishouling, Baoji, Shaanxi. This shows that both the dragon and the phoenix originated in the Neolithic period, which is seven to eight thousand years ago. The phoenix and the dragon have gradually become a pair in the legend, and they complement each other. The dragon has many changes while the phoenix has good virtues. From the Neolithic Age to the Spring and Autumn and the Warring States Periods when the theory of Yin and Yang and the Five Elements (metal, wood, water, fire and earth, held by the ancients to compose the physical universe) was popular, the phoenix almost appeared as something "yang". While in the early stages of its formation, the dragon is basically something "yin". The combination of dragon and phoenix reflects the view of yin and yang of the ancients. During the Warring States Period, a group of patterns that the dragon and phoenix entangle appeared. Later, the dragon symbolized the sun, and the phoenix, which was originally divided into yin and yang, gradually became a representative of yin after being contrast with the dragon. The emperors call themselves dragons, the queens call themselves phoenixes. Throughout the ages, the queen's appearance has been called "Feng Zi" and "Feng Yi" (that is the posture of phoenix); the crown worn by the queen is called "phoenix clothes with superb power"; the children born are called "the sons of the phoenix"; the edict issued by the queen is called "phoenix edict"; the cart used by the queen is called "fengche" or "fengnian" (that is the cart taken by the phoenix); the pavilion in the imperial palace is called "phoenix pavilion"; in the imperial room, the executive secretariat, which is the closest to the emperor's central institution in charge of the imperial court, is called "phoenix pool".

\section{The Empress}

Although Empress Wu is a woman, she took the throne successfully. For 1,380 years after her death, she has become the focus of attention and research by later generations. Just like the mausoleum with no inscription, there're no definite conclusions for her whole life. Hence, a unique historical and cultural phenomenon of the empress was derived.

Empress Wu's father, Wu Shiyue, run timber business, thereby the family of Wu gained fame and fortune. Later, Wu Shiyue got to know $\mathrm{Li}$ Yuan, and followed him closely with his whole heart. After the founding of the Tang Dynasty, he was named the founding earl, and rose to the official ranking of minister of the Ministry of Works [4,5]. Emperor Li Yuan designated Yang, the daughter of a prominent family in the Sui Dynasty, to marry Wu Shiyue. Later, Wu Shiyue was promoted to the governor of Lizhou (now Guangyuan, Sichuan). His wife, Yang, was pregnant with Empress Wu while boating on the Jiangtan Lake. Later, she gave birth to the baby in Lizhou [6]. Empress Wu's nickname was Yuanhua and Meiniang. When she was born, "the golden phoenix came to congratulate." Empress Wu entered the imperial palace at the age of 14 as a Cairen(a rank of ladies-in-waiting), and later became Zhaoyi(a kind of concubines of the emperor in ancient China), queen, empress dowager, and eventually became the emperor. She collected a treasure map in Luoshui River and claimed it as a gift given by the God, and described herself as the reincarnation of Maitreya Buddha in Mahamegha Sutra. Relying on the historical condition, specific marriage, and personal talents, Empress Wu wrote a glorious empress history. From the nomination of the queen in $655 \mathrm{AD}$, to 690 when she enthroned herself emperor, she audited politic affairs behind the curtain (historically known as two emperors in the imperial court) for 35 years. From 690 to 705 AD, Empress Wu changed the dynasty and enthroned herself emperor, ruling for 15 years. During her half-century rule, she was in charge of all over the country, maneuvered among various political groupings. She made the profound achievements that could be on a par with the rule of Zhenguan and lay a solid foundation for the prosperous rule of Kaiyuan [7,8].

\section{The Historical and Cultural Symbol of the Empress of the Phoenix Tree}

\section{Phoenix Symbolizes Empress Wu}

\section{Phoenix Tree and the Phoenix}

Firstly, legend has it that mankind has a dream of flying to the sky, the phoenix bird is the holy bird, and the bronze is the holy tree. 
The phoenix tree is regarded as a holy tree by the ancients. The bronze holy tree unearthed in Sanxingdui is a holy tree with compound characteristics. Its branches are divided into three layers, and there are 9 holy birds in it. It is just like the situation that "nine suns live on the branches below" (From the Book of Mountains and Seas). At the top of the bronze holy tree that was broken when it was unearthed, it is speculated that there should also be a holy bird symbolizing "a sun on the top branch" (The author believes that "the bronze" pronounces the same with the word "phoenix tree", the holy bird living in the holy tree is exactly the symbol of the phoenix living in the phoenix tree.).

Secondly, the ancients used the woods of phoenix trees to make the musical instrument. The ancients believed that music was related to the wind and the wind (Feng in Chinese pronunciation) sounds like the word "phoenix" (feng in Chinese pronunciation). Hence, it is believed that the phoenix lives in the phoenix tree.

Thirdly, since the phoenix is a bird, it must be connected with the tree, that is, the phoenix tree. The image of the phoenix is a synthesis of several natural objects. The roc mentioned in ancient books is also a phoenix. The Book of Mountains and Seas says, "There is a bird, shaped like a chicken, with colorful feathers all over its body, and its name is Phoenix."-The phoenix, the king of birds, governs the birds all over the world. The phoenix trees are luxuriant, densely shaded, and extremely tall, which have accumulated rich cultural connotations. The phoenix knows the rise and fall of a nation, boasts good virtues, and dwells exclusively on phoenix trees, thereby the phoenix trees are regarded as auspicious trees in the past dynasties. The well-off family in history often planted phoenix trees in their yards because the phoenix trees are not only vigorous, but also the symbol of auspiciousness. There is a saying in The Book of Songs that the phoenix tree grows luxuriantly, causing the phoenix to sing. During the Spring and Autumn period, King Wu, Fuchai, built a phoenix garden in the yard. "The phoenix garden is in the Wu Palace. It's the old garden of King Wu, also named Qinchuan."(A Wonder and Tangle Wood Tales, Liang Renfang). During the Warring States Period, in Zhuangzi - Waipian - Qiushui, there is "The phoenix sets off from the South Sea and flies to the North Sea. It only inhabits when it encounters phoenix trees. It only eats bamboo and only drinks sweet springs", which reflects the phoenix does not live with the common birds, and shows the nobleness of the phoenix tree. The Zhou dynasty has been crowned the first place among the dynasties for it lasts 800 years. And the reason for that is also related to the phoenix tree. Shuyu is the younger brother of King Zhou Cheng. One day, Shuyu played with King Cheng. King Cheng cut a leaf of the phoenix tree into the shape of a Jade Tablet and said to Shuyu: "I will give you the seal of Jade Tablet." Shuyu was happy and told this to Zhou Gong. ...Therefore, King Zhou Cheng bestowed Jin as a fief to Shuyu (Springs and Autumns of Master L ̈̈̈ Z Zhongyan) The ancient kings valued the phoenix tree, which was called the gentleman of the book. King Zhou Cheng planted the phoenix trees in the courtyard, and cut the leaf and bestowed a fief to his brother [9].

After observation, the author believes that phoenix living in the phoenix tree is a human association of the ecological pictogram of the phoenix tree. The phoenix tree belongs to the terminal panicle. In late June, flowers of phoenix trees appear in temples, royal palaces, parks, courtyards, roadsides, and jungles. They are calm and noble, indisputably beautiful. They are like phoenixes living in the top of the tree, or holy birds flying into the sky, with both spiritual charm and royal temperament, which makes people stunned and respectful. Perhaps this is the original ecological image of "Planting a phoenix tree and attracting the phoenix"!

\section{Phoenix and the Empress}

Empress $\mathrm{Wu}$ described herself as a phoenix, and was the incarnation of phoenix, so she enthroned herself emperor. There are also many images, myths and legends of Empress Wu as a phoenix. The memorials and cultural customs of later generations also regard her as a phoenix.

1. From the analysis of natural geomantic omen in Lizhou where Empress Wu was born, the dragon is in the Wulong Mountain and phoenix is in the Phoenix Mountain, and both of them are auspicious. The author observes that the water of the Jialing River flows between the Wulong and Phoenix mountains, through the Wulong Lake, and then joins with the two waters of the Nanhe River. The whole view is just like the picture of Yin-Yang Fishes, which integrates the spirit of heaven and earth, and presents a magical golden triangle, namely the beautiful ancient city of Lizhou. When the phoenix flew out of here, it was named Phoenix Mountain.

2. From the legend that Empress Wu was born "from the reincarnation of the phoenix", this story was first spread in Empress Wu's hometown, Lizhou (Guangyuan), and was included in writings by some literati after the Mid-Tang Dynasty. The following is about the legend: At that time, his parents and some people were having fun on the river boating. Suddenly, a dragon jumped into the sky from the Xishan Mountain, rushed straight to their boat, and flew around the ship and then flew to Chang'an. After that, Ms. Yang became pregnant. The legend has been passed down to today. After Li Shangyin, a poet of the late Tang Dynasty, came to Lizhou in $851 \mathrm{AD}$, he visited the place where Ms. Yang was pregnant and wrote the poem "Lizhou Jiangtan Lake" and noted that it was "the place where Ms. Yang was pregnant with Empress Wu". The poem vividly depicts the scene of the dragon and man mingling and becoming pregnant with Empress Wu. Empress $\mathrm{Wu}$ was deeply affectionate with her hometown. So Wu'nu Mountain was changed into Wulong Mountain, and Jiangtan Lake into Wulong Lake.

3. Yuan Tiangang made an astrology. Yuan Tiangang, a master of astrology, concluded that there would be the emperor of the new dynasty born in Langzhong. Therefore, he cut into the mountain at the dragon neck of Panlong Mountain where the image of the dragon was formed, so as to stop this omen. It is said that after the dragon neck was sawed off, the omen went to Guangyuan. In the early years of the Tang Dynasty, he went south from the capital of Chang'an to Shu (Sichuan), and arrived at Lizhou City on the day of Dragon Boat Festival. Suddenly, a dragon sprang from the depths of the river and 
flew towards the Xishan Mountain; at the same time, a phoenix sang on the top of the Dongshan Mountain, and then flew to the north. Yuan Tiangang said, "This is called the prosperity brought by the dragon and the phoenix, and there must be an important man born here." In the first month of the next year, the wife of Governor Wu gave birth to a girl. Governor Wu asked Yuan Tiangang to look up the physiognomy for her. At that time, Empress Wu was wearing a boy's costume and held by a wet nurse. After looking at her for a while, Yuan Tiangang exclaimed, "The center of the frontal bone shows some emperor's temperament. Her eyes are similar to those of a dragon and the neck is like that of a phoenix, which is the look of the most distinguished person." When he learned that it was a girl, he exclaimed and asserted, "This girl may become the ruler of the country!"

4. Yuan Tiangang met a phoenix at Chaotian Pass. On the Double Ninth Festival, Yuan Tiangang saw a woman with a red ribbon fluttering around her transformed into a colorful phoenix surrounded by nine golden dragons, and the colorful phoenix changed into an emperor wearing a golden crown and holding an imperial jade seal. Astonished, Yuan Tiangang fallen off and shouted, "Your Majesty, Heaven's order is hard to violate!" It turns out that it is Meiniang on the plank road. Decades later, Empress Wu enthroned herself on the Double Ninth Festival and changed the Tang Dynasty to Zhou Dynasty, and the reign title was "Tianshou".

5. The imagination of Empress Wu when she entered the imperial palace for the second time. When Empress Wu entered the palace for the second time, she seemed to see a colorful phoenix singing and there were other birds singing around the phoenix. So being the empress in the palace became her goal.

6. Empress Wu's calligraphy is "Feibai calligraphy with phoenix figure" [7]. She used to be "Wu Zhaoyi". Her mother Yang's Shun Mausoleum is called "Wangfengtai", and its mausoleum is called "Wangfengtai Stele" in history.

7. Empress Wu was the queen first, then the empress dowager, and finally took the throne. She referred to herself as the phoenix. The empress dowager met the petition team that supported her as the emperor in the gate tower. According to legend, something auspicious was observed. Someone saw a phoenix flying out of Mingtang and landing on the phoenix tree on the Suzhengtai (the supervisory agency in Tang Dynasty) of Shangyang Palace in Luoyang. Empress Wu hurriedly led the crowd to Mingtang and watched this scene. The phoenix flew southeast once it saw Empress Wu. But the rosefinches gathered in the hall, dancing for a long time and refused to leave.... Seeing this, a minister immediately knelt down, and explained to Empress Wu, "The phoenix symbolizes you, and these rosefinches just represent us. It flies to the Suzhengtai and leaves as soon as seeing you, which is to imply that you should be enthroned. If you still do not take the throne, it will go against the will of God, the rosefinches will not leave, and we will kneel down forever!" Finally, Empress Wu conformed to the so-called will of God. On September 9th, 690, Wearing the imperial robe, she boarded the Zetian Gate Tower and announced the start of the enthronement ceremony. Later, she ordered an amnesty for the country. And rosefinches flew away as expected [10-12]. The model that a phoenix controls nine dragons in Mingtang symbolizes her Wu Zhou regime, which is exactly the portrayal of Empress Wu.

\section{Phoenix Tree and the Empress}

Guangyuan is the birthplace of Empress Wu where verdant phoenix trees are widely planted. The phoenix tree contains Empress Wu's nostalgia complex. 1,380 years ago, the story from Mrs. Yang's "Being Pregnant on the Jiangtan Lake" to "Golden Phoenix Brings Good Fortune" and "Paranormal Things Echo" took place here. From the standpoint of historical materialism, myths and legends are spread by later generations. They describe that Empress Wu took the throne as "the unity of Heaven and Humanity". It is this legendary and paranormal story that makes this place fascinating. The phoenix brings auspiciousness and peace and Empress Wu brings safe and sound. Although the phoenix had gone, today we can still see the phoenix trees in the Five Buddha Towers in Huangze Temple in Guangyuan where Mrs. Yang was pregnant with Empress Wu. The phoenix trees on the Phoenix Mountain are verdant and tall, with legends of immortality. Based on Empress Wu's nostalgia complex, the phoenix tree in Guangyuan embodies the profound historical and cultural implication of the empress.

\section{Phoenix Tree Symbolizes the Body of the Empress as a Sacred Tree of Buddhism}

\section{Phoenix Tree-Sacred Tree of Chinese Buddhism, Phoenix- Chinese Buddhist Bird}

Phoenix tree becomes the sacred tree of Chinese Buddhism because Chinese Buddhist disciples have chosen this tree, which adapts to the local climate and has many similarities with the bodhi ("pu ti" in Pinyin) tree, to replace the bodhi tree.

According to history, in $502 \mathrm{AD}$, the monk Zhiyue Sanzang brought the bodhi tree back from Xizhu (India) and planted it in Guangzhou. Real bodhi trees are only planted in the tropics and subtropics, but in the temperate zone and the vast northern regions of China, it is difficult for bodhi trees to survive the winter [13]. In China, only the south and southeast coastal areas are suitable for growth. Therefore, in history, Chinese Buddhist disciples had to choose some tree species that could adapt to the local climate instead of bodhi trees. The phoenix tree is tall and straight with big and green leaves and deep shade. It has been widely planted in various provinces and regions in China for more than 2,000 years, so it has become the best choice for the replacement.

On the other hand, because the phoenix tree has many similarities with the bodhi tree, so it becomes one of the sacred trees of Chinese Buddhism with the ginkgo and horse chestnut trees. First of all the similar religious connotations of the phoenix tree and the bodhi tree. "Pu ti" is the transliteration of the ancient Hindi language "Bodhi", which means enlightenment and wisdom. In plant taxonomy, the Latin 
name of bodhi tree is "Ficus religiosa", which means sacred religion. The phoenix tree also has the meaning of nobility and enlightenment. Second, the temporal and spatial distribution. Bodhi trees are widely planted in jungle temples in India, Sri Lanka and Myanmar. Devout Buddhists regard them as sacred trees and admire them very much. Phoenix trees are also widely distributed in China's courtyards, palaces and jungle temples, and are regarded as sacred and auspicious trees. Third, the individual characteristics. The bodhi tree is a tall tree with smooth or slightly angled bark. The crown is round or obovate, and the ground was covered by the luxuriant branches and leaves. The leaf base is heart-shaped, ark green, with clear net-like veins called "Bodhi yarn”, which is regarded as a sacred tree. The phoenix tree is a tall tree with the green bark, the luxuriant branches, and the round crown. The petiole is nearly the same length as the leaf, the broad leaf is like a lotus, and the heart-shaped leaf base is like the heart of the Buddha, which is elegant and delightful. The clear net-like veins are especially like "Bodhi yarn." Fourth, the plant characteristics. The trunk of bodhi tree and phoenix tree is stout and majestic. The crown is like a pavilion, which is huge. The leaf is heart-shaped, and the surface is smooth. Fifth, the cultivation methods. Both bodhi trees and phoenix trees can be cultivated by cuttings with beautiful appearance and gorgeous leaves. Finally, the similar uses of the two. Their leaves, flowers, and bark can be used in medicine [14].

In ancient Chinese legend, the phoenix was formed by the goldenwinged bird of Buddhism. In addition, it is said that the peacock once swallowed the Tathagata, and the Tathagata came out of her back. The Tathagata wanted to kill her, but was discouraged by the Lantern Buddha, saying that since you came out of her body, and you killed her like killing your mother. So the Tathagata forgave the peacock and named her "Mahā-mayūrī-vidyā-rājñ̄ì" (means the Great King of the Peacock). This shows that phoenix is also a Buddhist bird in Chinese myths.

\section{Empress Wu - Buddhist Body}

1) Empress Wu has been inextricably bound to Buddhism since she was a child. Her mother, Yang, believed in Buddhism since she was young, and even prayed for her father in Buddhism for more than a decade, so that she didn't get married until she was in her forties. It is said that when Wu was born, in Zhengjia Mountain (Lotus Village) outside Lizhou, the withered lotus leaves in late autumn regenerated new leaves, and golden lotus blossomed out, and large tracts of beautiful auspiciousness suddenly floated in the sky. Further research shows that Empress Wu's real name is "Wu Yuanhua" [7]. "Yuanhua" is the meaning of the initial light and unique youth. "Yuanhua" is close to "Mahavairocana", which reminds people of the Buddhist scene that the sun and the moon are in the sky and the light is so bright.

2) Wu believed in Buddhism from an early age, facing the ancient Buddha with a lantern, chanting and worshiping. In her youth, she also used to be a nun with "Mingkong" as her Buddhist name. When she was 21 , Wu worked as a nun at a Buddhist temple. Her name was "Ming Kong", which means the Dharma and all void space-directions, which is very similar to the Buddhist situation. This is also the reason why she created the words "Ming and Kong" into the word "Zhao" after she became empress. The meaning of Yuanhua-Ming Kong-Zhao is same.

3) When she was queen, $\mathrm{Wu}$ donated 20,000 pieces of private storage to carve a "Locanabuddha" at Fengxian Temple in Longmen, Luoyang, and personally attended the opening ceremony of it. Locanabuddha totally has the facial features of oriental women and is known as "the most beautiful Buddha in the world". After research, the "Locanabuddha" of Fengxian Temple is Wu's appearance when she was in Xianheng for three years (672) and was about 4 years old [7]. The Buddha, also known as "Maha^vairocana", is a transformation of the Buddha. In China, it is often regarded as "sambhogakaya", meaning the "prevailing light". Locana means vast wisdom and prevailing light, and its image is a vivid embodiment of Buddhist teachings and an example of the perfect combination of divinity and human nature.

4) Wu is the rebirth of Maitreya Buddha. As a politician, Wu is a theist. She highly values Buddhism, not only believing in it, but also making use of it. She was favored, murdered people to obtain the position, coerced into resignation, and served the imperial power with the help of theocracy. The Buddhist theory of reincarnation found the basis for $\mathrm{Wu}$ as a female emperor. Under the banner of Maitreya Buddha, the Queen $\mathrm{Wu}$ instructed to annotate and promote Dayun Scriptures which said that "the Buddha tells a heavenly maiden named "Jingguang" that she will transform the Bodhisattva, that is, the female will be the king." In Dayunjing Shu, Feng Xiaobao directly stated that $\mathrm{Wu}$ was the reincarnation of Maitreya Buddha, transforming the Tang Dynasty into Zhou. "She was the ruler of the world", and then finally became a Buddha.

5) The stone statue of the Queen $\mathrm{Wu}$ of Huangze Temple in Guangyuan is a Bodhisattva statue carved according to Wu's face in her old age, implying the historical fact that she was the rebirth of Maitreya Buddha and ascended to the throne in her later years.

\section{Phoenix Tree Symbolizes the Only Female Emperor}

1) The trunk of Phoenix tree is straight and tall, with few branches, symbolizing that $\mathrm{Wu}$ has taken a firm step towards the ultimate goal of life since her parents named "Yuanhua". Phoenix tree symbolizes the only female emperor in the era of patriarchal rule, with a woman as the system and the emperor. It can be said that she was the only person in ancient and modern times, walking alone for thousands of years. From entering the palace to becoming the empress, Wu basically relied on personal struggle and continuous self-improvement along the way. She had an indomitable will to do everything, the lofty words of "enforcing justice on behalf of heaven", and an ambition to achieve a great cause. She is aggressive, resourceful, resolute, decisive, unafraid, and indomitable, and has a fierce personality that is not afraid of everything. At that 
time, the focus of the political struggle in the Tang Dynasty focused on the interior of the imperial court. Empress $\mathrm{Wu}$ encountered very strong opposition forces in the process of her uproar in the Tang Dynasty. Liu Shuang, Changsun Wuji, Han Yi, Yu Zining, Pei Yinjian, Laiji, Shangguan Yi and so on hurt Wu before, $\mathrm{Xu}$ Jingye in Yangzhou, Li Yuanjia in Jiangzhou, and Li Zhen in Runan [7] armed against Wu later, however, they all failed to defeat her.

2) The phoenix tree is tall and straight, with a graceful posture and the natural and imposing demeanor. Its magnificent beauty is just what Empress Wu likes. The phoenix tree with green branches is lush and elegant, and the shade of dense leaves relieves the heat of summer, symbolizing Empress Wu's life of benefiting the world and the people. Empress Wu had "a wisdom of knowing people and a heart of loving talent." She employed the right people, listened to the right words, used civil and military methods, and made great achievements, which can be called an iron-handed monarch in Chinese history $[7,15]$. Empress Wu's attitude towards the Manifesto Against Wu Jao in the mutiny in Yangzhou shows her capacity; the opening of disciplines to select scholars reflects her wisdom of knowing people; and her control of villains and gentlemen embodies her skill of employing people.

3) The phoenix tree stands in the wind, not afraid of the cold, symbolizing that the life of Empress $\mathrm{Wu}$ is a vigorous life, a rebellious life, and a life of subverting patriarchal political thought. Mr. Lu Xun once said "who dares to say men are superior to women when Wu became the emperor?" In the feudal society in which men were superior to women, Empress Wu was stigmatized as "a hen crowing in the morning", which always belittled the empress consciously $[16,17]$. Today, history has objectively evaluated this great woman.

\section{Phoenix Symbolizes the Affection of the Empress}

Phoenix symbolizes love which refers to the affection of the empress. Empress Wu was a ruthless monarch who murdered countless people, but she was also an affectionate woman who loves so much. She went to the palace at the age of 14 to be a talented scholar for Emperor Taizong, Li Shimin, but was not spoiled by Taizong. “The leaves of the phoenix tree by the well are getting yellow, and you can know the frost in the night without rolling the pearl curtain. The smoked cage and jade pillow looks like a haggard face, lying down and listening to the voice from the South Palace." (The Poem of the Changxin Palace by Wang Changling). "The rain drenched on the leaves of the phoenix tree at the night, full of autumn, and beat on the plantains, making people sorrowful. In the middle of the night, I returned to my hometown in my dream." (Double Tone - Water Fairy · Night Rain by Xu Zaisi). This poem cannot stopping the melancholy thoughts of young $\mathrm{Wu}$ in the palace. In the period of loss and loneliness, Wu was dressed in court dress and wrote a love poem Set to the Tune Ruyi Niang in Ganye Temple: "Watching red turn to green, my thoughts entangled and scattered. I am disheveled and torn from my longing for you, my lord. If you fail to believe that of late I have constantly shed tears, open the chest and look for the skirt of pomegranate-red."
[10] This poem is so sorrowful, even Li Bai had a lot of emotion after reading it, and felt inferior to himself. Empress Wu, who trained a steed with a dagger, missed her lover day and night, and her eyes were dim with tears, regarding the red flowers as green phoenix tree leaves.

"The autumn rain in the midnight falls on the phoenix tree leaves, and the sound of the leaves tells of separation." (Zhegutian - A Little Bit of Red is Dying by Zhou Zizhi). The pronunciation of "Wu (means phoenix)" and "Wu (means I), and "Tong (means phoenix)" and "Tong (means together)" is similar. The tall phoenix tree symbolizes that the emperor Gaozong, Li Zhi, and Wu Yuanhua made an oath to weep when they met under the phoenix tree in Ganye Temple. Because of missing $\mathrm{Li}$, Wu was awakened by the rain of phoenix tree in autumn night after falling into a dream. There is no doubt that the phoenix tree becomes a symbol of love between $\mathrm{Li}$ and $\mathrm{Wu}$. At the age of 27, Wu became the queen of $\mathrm{Li}$. The green leaves and branches of Phoenix tree symbolize her good relationship with $\mathrm{Li}$. When she was 55 years old, Li died of illness in Zhenguan Hall in Luoyang. Before his death, he wrote in the edict that "if there is anything that cannot be decided on military and national affairs, listen to the decision of the empress." The final decision-making power of the empire was handed over to Empress Wu. At the age of 62, she became the emperor of the Great Zhou Dynasty and still had her own emotional world in the cruel political struggle. The empress, who was over 70, was still alone, and she was eager to be a "Ruyi Niang" again. Thus, the Phoenix tree symbolizes her complex emotional life.

\section{The Falling Leaves of Phoenix Tree in Autumn Shows that Empress Wu Lost Her Kingship and Became Queen}

The leaves of phoenix tree are luxuriant, but they fall earliest in autumn. "One leaf of phoenix tree falls, the whole world knows autumn to come." (Erruting Qunfangpu by Wang Xiangjin). Fallen leaves are not declining, which is a natural response of plants to adapt to the environment, so the phoenix tree is a symbol of the autumn. Empress Wu, who abdicated from the throne in Shangyang Palace in Luoyang, stood in the cold autumn wind and looked at the shade of sparse phoenix trees under the moonlight in the deep courtyard. She sighed her glorious past and returned Zhou to Tang Dynasty. When she was dying, she removed to the Kingship and said she was still the queen. That is to say, Empress Wu finally gave up the independence of women and returned to the male power society, which was inevitable at that time, and was what she had to do. The leaves of phoenix tree fall to know autumn, and the leaves return to their roots. Although Empress Wu conquered numerous challenges, she could not escape the secular convention in the end.

\section{Ecological Significance of the Images of Phoenix Tree, Phoenix, and Empress}

The interpretation of the ecological significance of the images of phoenix tree, phoenix and empress can guide people to deepen the study of the empress culture in the forest culture. The image of phoenix tree and empress culture does not exist alone, it can form a compound image with phoenix, or it can be used individually. At the same time, when we interpret the image of phoenix tree and empress culture, we must put it in the whole historical and cultural 
atmosphere, and combine other images to grasp it as a whole. Only in this way can we better interpret the image of phoenix tree, which has the connotation of empress culture [18]. At the same time, we can carry forward phoenix culture and empress culture to create a characteristic forest cultural creative park, build a forest cultural city, and promote their ecological civilization value [19]. We can plant phoenix trees in the countryside of Guangyuan, in front and back of the courtyard, on both sides of the road, and in urban gardens. The green lines of roads, railways and rivers make up the phoenix, and the large green areas around the city set off the flying phoenix, which can enhance the image of the city. Phoenix tree symbolizes ecological civilization, and phoenix symbolizes human dream of flying into the sky, so phoenix tree and phoenix share a harmonious and wonderful life desire. In this beautiful city, as the king of birds, phoenix is the embodiment of truth, goodness and beauty. As its only habitat and auspicious tree species, phoenix tree can bring happiness and good luck to residents and tourists, so as to enhance the tourism charm of Guangyuan City.

\section{Acknowledgment}

Professor Chen Jiancheng and Professor Zheng Xiaoxian of Beijing Forestry University, Director Jiang Dayong of Sichuan Forestry Department, Director Chen Yang of Guangyuan City Library, Director Bai Chaomao of Fenghuangshan Park Management Office of Guangyuan City, Pu Zhitian, a senior engineer from the Landscape Department of Guangyuan Construction Bureau, Director Bai Jian of Guangyuan Culture Bureau, Li Qianxiu, the chairman of the Lizhou District of CPPCC and Writers' Association, etc. Thank all of you for your help!

\section{References}

1. Jiang Kongyang, Zhu Liyuan (1999) Aesthetic Principles [M]. Shanghai: East China Normal University Press.

2. Chen Jiru (2007) Sketches by the Little Window [M]. Tianjin: Baihua Literature and Art Publishing House.

3. Guan Chuanyou (2007) Historical and Cultural Implication of Planting Phoenix Trees in China. China Urban Forestry 5: 40-41.

4. Xin Mo (1988) Wu Zetian and Huangze Temple [M]. Chengdu: Sichuan Art Publishing House 36-39.

5. Ma Yunhuan (2000) Guangyuan Trip to Shu Road, Jianmen [M]. Xian: Taibai Literature and Art Publishing House 11: 12.

6. Hu Ji (1986) Biography of Wu Zetian [M]. Xi’an: Sanqin Publishing House.

7. Chen Yang (2009) Decrypt of Wu Zetian [M]. Beijing: Popular Literature and Art Publishing House.

8. Li Qianxiu (2000) Wu Qianqiu [M]. Chengdu: Sichuan People’s Publishing House $2-4$.

9. [9] Liu Zongyuan (1987) Discrimination of Giving Leaves of Phoenix Tree to Brother [M]. Changsha: Yuelu Book Society 1987: 203-205.

10. Meng Man (2008) Meng Man Talking about the Tang Dynasty: Wu Zetian [M] Nanning: Guangxi Normal University Press 2, 3, 27, 185, 186.

11. Zhang Wendi (2006) Poems about the Empress's Hometown [M]. Beijing: Popular Literature and Art Publishing House 175.

12. Shi Yongtao (2007) From Daming Palace to Luoyang Mingtang [N]. Urban Economic Bulletin 5: 6-26.

13. Yu Liangxiu (2002) Chengdu Landscape Plants [M]. Chengdu: Sichuan Science and Technology Publishing House.
14. Chen Youmin (1990) Landscape Dendrology [M]. Beijing: China Forestry Publishing House 400-403: 570, 571.

15. Hui Huanzhang, Wu Qiao (2002) 100 Secrets of Wu Zetian [M]. Xian: Xian Publishing House 75-78.

16. Li Daming (2005) Twenty-five Histories [M]. Chengdu: Bashu Publishing House 511-514.

17. He Kaisi (2008) The Light of Women under the Five-ring Flag" [N]. Sichuan Daily 08-15 (B4).

18. Su Zurong (2001) Introduction to Forest Aesthetics [M]. Shanghai: Xuelin Publishing House 275: 316.

19. Wu Zhiwen (2008) Development of Forest Culture, Forestry Creative Industry and New Forestry Economic Growth Point. World Forestry Research 9: 184-192.

\section{Citation:}

Zhiwen W, Songyuan W, Shujun Y (2021) Phoenix Tree, Phoenix and Empress: Empress Historical-Cultural Symbol of Phoenix Tree and its Good Environmental Civilized Value. Aquac Fish Stud Volume 3(4): 1-7. 